\title{
ALBEDO ENHANCEMENT BY STRATOSPHERIC SULFUR INJECTIONS: A CONTRIBUTION TO RESOLVE A POLICY DILEMMA?
}

\author{
An Editorial Essay
}

Fossil fuel burning releases about $25 \mathrm{Pg}$ of $\mathrm{CO}_{2}$ per year into the atmosphere, which leads to global warming (Prentice et al., 2001). However, it also emits $55 \mathrm{Tg} \mathrm{S}$ as $\mathrm{SO}_{2}$ per year (Stern, 2005), about half of which is converted to sub-micrometer size sulfate particles, the remainder being dry deposited. Recent research has shown that the warming of earth by the increasing concentrations of $\mathrm{CO}_{2}$ and other greenhouse gases is partially countered by some backscattering to space of solar radiation by the sulfate particles, which act as cloud condensation nuclei and thereby influence the micro-physical and optical properties of clouds, affecting regional precipitation patterns, and increasing cloud albedo (e.g., Rosenfeld, 2000; Ramanathan et al., 2001; Ramaswamy et al., 2001). Anthropogenically enhanced sulfate particle concentrations thus cool the planet, offsetting an uncertain fraction of the anthropogenic increase in greenhouse gas warming. However, this fortunate coincidence is "bought" at a substantial price. According to the World Health Organization, the pollution particles affect health and lead to more than 500,000 premature deaths per year worldwide (Nel, 2005). Through acid precipitation and deposition, $\mathrm{SO}_{2}$ and sulfates also cause various kinds of ecological damage. This creates a dilemma for environmental policy makers, because the required emission reductions of $\mathrm{SO}_{2}$, and also anthropogenic organics (except black carbon), as dictated by health and ecological considerations, add to global warming and associated negative consequences, such as sea level rise, caused by the greenhouse gases. In fact, after earlier rises, global $\mathrm{SO}_{2}$ emissions and thus sulfate loading have been declining at the rate of $2.7 \%$ per year, potentially explaining the observed reverse from dimming to brightening in surface solar radiation at many stations worldwide (Wild et al., 2005). The corresponding increase in solar radiation by $0.10 \%$ per year from 1983 to 2001 (Pinker et al., 2005) contributed to the observed climate warming during the past decade. According to model calculations by Brasseur and Roeckner (2005), complete improvement in air quality could lead to a decadal global average surface air temperature increase by $0.8 \mathrm{~K}$ on most continents and $4 \mathrm{~K}$ in the Arctic. Further studies by Andreae et al. (2005) and Stainforth et al. (2005) indicate that global average climate warming during this century may even surpass the highest values in the projected IPCC global warming range of $1.4-5.8^{\circ} \mathrm{C}$ (Cubasch et al., 2001).

By far the preferred way to resolve the policy makers' dilemma is to lower the emissions of the greenhouse gases. However, so far, attempts in that direction have 
been grossly unsuccessful. While stabilization of $\mathrm{CO}_{2}$ would require a $60-80 \%$ reduction in current anthropogenic $\mathrm{CO}_{2}$ emissions, worldwide they actually increased by $2 \%$ from 2001 to 2002 (Marland et al., 2005), a trend, which probably will not change at least for the remaining 6-year term of the Kyoto protocol, further increasing the required emission restrictions. Therefore, although by far not the best solution, the usefulness of artificially enhancing earth's albedo and thereby cooling climate by adding sunlight reflecting aerosol in the stratosphere (Budyko, 1977; NAS, 1992) might again be explored and debated as a way to defuse the Catch-22 situation just presented and additionally counteract the climate forcing of growing $\mathrm{CO}_{2}$ emissions. This can be achieved by burning $\mathrm{S}_{2}$ or $\mathrm{H}_{2} \mathrm{~S}$, carried into the stratosphere on balloons and by artillery guns to produce $\mathrm{SO}_{2}$. To enhance the residence time of the material in the stratosphere and minimize the required mass, the reactants might be released, distributed over time, near the tropical upward branch of the stratospheric circulation system. In the stratosphere, chemical and micro-physical processes convert $\mathrm{SO}_{2}$ into sub-micrometer sulfate particles. This has been observed in volcanic eruptions e.g., Mount Pinatubo in June, 1991, which injected some 10 $\mathrm{Tg} \mathrm{S}$, initially as $\mathrm{SO}_{2}$, into the tropical stratosphere (Wilson et al., 1993; Bluth et al., 1992). In this case enhanced reflection of solar radiation to space by the particles cooled the earth's surface on average by $0.5^{\circ} \mathrm{C}$ in the year following the eruption (Lacis and Mishchenko, 1995). Although climate cooling by sulfate aerosols also occurs in the troposphere (e.g., Ramaswamy et al., 2001), the great advantage of placing reflective particles in the stratosphere is their long residence time of about 1-2 years, compared to a week in the troposphere. Thus, much less sulfur, only a few percent, would be required in the stratosphere to achieve similar cooling as the tropospheric sulfate aerosol (e.g., Dickinson, 1996; Schneider, 1996; NAS, 1992; Stern, 2005). This would make it possible to reduce air pollution near the ground, improve ecological conditions and reduce the concomitant climate warming. The main issue with the albedo modification method is whether it is environmentally safe, without significant side effects.

We will next derive some useful metrics. First, a loading of $1 \mathrm{Tg} \mathrm{S}$ in the stratosphere yields a global average vertical optical depth of about 0.007 in the visible and corresponds to a global average sulfur mixing ratio of $\sim 1 \mathrm{nmol} / \mathrm{mole}$, about six times more than the natural background (Albritton et al., 2001). Second, to derive the radiative forcing caused by the presence of $1 \mathrm{Tg} S$ in the stratosphere, we adopt a simple approach based on the experience gained from the Mount Pinatubo volcanic eruption. For the Mount Pinatubo eruption, Hansen et al. (1992) calculated a radiative cooling of $4.5 \mathrm{~W} / \mathrm{m}^{2}$ caused by $6 \mathrm{Tg} \mathrm{S}$, the amount of $\mathrm{S}$ that remained in the stratosphere as sulfate six months after the eruption from initially $10 \mathrm{Tg} \mathrm{S}$ (Bluth et al., 1992). Linear downscaling results in a sulfate climate cooling efficiency of $0.75 \mathrm{~W} / \mathrm{m}^{2}$ per $\mathrm{Tg} \mathrm{S}$ in the stratosphere. The estimated annual cost to put $1 \mathrm{Tg} \mathrm{S}$ in the stratosphere, based on information by the NAS (1992), at that time would have been US \$25 billion (NAS, 1992; Ron Nielsen, personal communication). Thus, in order to compensate for enhanced climate warming by the removal of 
anthropogenic aerosol (an uncertain mean value of $1.4 \mathrm{~W} / \mathrm{m}^{2}$, according to Crutzen and Ramanathan (2003)), a stratospheric sulfate loading of $1.9 \mathrm{Tg} \mathrm{S}$ would be required, producing an optical depth of $1.3 \%$. This can be achieved by a continuous deployment of about 1-2 Tg S per year for a total price of US \$25-50 billion, or about \$25-50 per capita in the affluent world, for stratospheric residence times of 2 to 1 year, respectively. The cost should be compared with resulting environmental and societal benefits, such as reduced rates of sea level rise. Also, in comparison, current annual global military expenditures approach US $\$ 1000$ billion, almost half in the U.S.A. The amount of sulfur that is needed is only $2-4 \%$ of the current input of $55 \mathrm{Tg}$ S/year (Stern, 2005). Although the particle sizes of the artificial aerosols are smaller than those of the volcanic aerosol, because of greater continuity of injections in the former, the radiative forcings are rather similar for effective particle radii ranging between 0.1 and $1 \mu \mathrm{m}$ (see Table 2.4, page 27, Lacis and Mishchenko, 1995). However the smaller particles have a longer stratospheric residence time, so that less material needs to be injected to cool climate, compared to the volcanic emission case. It should be mentioned that Anderson et al. $(2003 \mathrm{a}, \mathrm{b})$ state that the radiative cooling by the aerosol could be much larger than the figure of $1.4 \mathrm{~W} / \mathrm{m}^{2}$, derived by Crutzen and Ramanathan (2003), which is based on the assumption of constant relative humidity in the troposphere. If Anderson et al. (2003a,b) are indeed correct, the result might be a stronger climate heating from air pollution cleanup than derived above (see also Andreae et al., 2005).

To compensate for a doubling of $\mathrm{CO}_{2}$, which causes a greenhouse warming of $4 \mathrm{~W} / \mathrm{m}^{2}$, the required continuous stratospheric sulfate loading would be a sizeable $5.3 \mathrm{Tg}$ S, producing an optical depth of about 0.04 . The Rayleigh scattering optical depth at $0.5 \mu \mathrm{m}$ is about 0.13 , so that some whitening on the sky, but also colorful sunsets and sunrises would occur. It should be noted, however, that considerable whitening of the sky is already occurring as a result of current air pollution in the continental boundary layer.

Locally, the stratospheric albedo modification scheme, even when conducted at remote tropical island sites or from ships, would be a messy operation. An alternative may be to release a S-containing gas at the earth's surface, or better from balloons, in the tropical stratosphere. A gas one might think of is COS, which may be the main source of the stratospheric sulfate layer during low activity volcanic periods (Crutzen, 1976), although this is debated (Chin and Davis, 1993). However, about $75 \%$ of the COS emitted will be taken up by plants, with unknown long-term ecological consequences, $22 \%$ is removed by reaction with $\mathrm{OH}$, mostly in the troposphere, and only $5 \%$ reaches the stratosphere to produce $\mathrm{SO}_{2}$ and sulfate particles (Chin and Davis, 1993). Consequently, releasing COS at the ground is not recommended. However, it may be possible to manufacture a special gas that is only processed photochemically in the stratosphere to yield sulfate. The compound should be non-toxic, insoluble in water, non-reactive with $\mathrm{OH}$, it should have a relatively short lifetime of less than about 10 years, and should not significantly contribute to greenhouse warming, which for instance disqualifies $\mathrm{SF}_{6}$. 
The albedo modification scheme presented here has been discussed before, however, without linking opposite climate warming and improved air quality considerations. Instead of sulfur, it has also been proposed to launch reflecting small balloons or mirrors, or to add highly reflective nano-particles of other material than sulfur (Teller et al., 1997; Keith, 2000). An interesting alternative could be to release soot particles to create minor "nuclear winter" conditions. In this case earth's albedo would actually decrease, but surface temperatures would, nevertheless, decline. Only $1.7 \%$ of the mass of sulfur would be needed to effect similar cooling at the earth's surface, making the operations much cheaper and less messy. However, because soot particles absorb solar radiation very efficiently, differential solar heating of the stratosphere could change its dynamics. It would, however, also counteract stratospheric cooling by increasing $\mathrm{CO}_{2}$ and may even prevent the formation of polar stratospheric cloud particles, a necessary condition for ozone hole formation.

Since it is likely that the greenhouse warming is substantially negated by the cooling effect of anthropogenic aerosol in the troposphere, by 25-65\% according to an estimate by Crutzen and Ramanathan (2003), but possibly greater (Anderson et al., 2003a,b), air pollution regulations, in combination with continued growing emissions of $\mathrm{CO}_{2}$, may bring the world closer than is realized to the danger described by Schneider (1996): "Supposing, a currently envisioned low probability but high consequence outcome really started to unfold in the decades ahead (for example, $5^{\circ} \mathrm{C}$ warming in this century) which I would characterize as having potential catastrophic implications for ecosystems ... Under such a scenario, we would simply have to practice geo-engineering..."

There are some worrying indications of potentially large climate changes: for instance the locally drastic atmospheric warming by up to $3 \mathrm{~W} / \mathrm{m}^{2}$ per decade in Alaska due to surface albedo decreases through tree and shrub expansion (Chapin III et al., 2005), the projected increase in surface temperatures by $2-3 \mathrm{~K}$ by the middle of this century in Africa even with the Kyoto protocol in force (B. Hewitson, University of Cape Town, quoted by Cherry, 2005) with great impacts on biodiversity, and potentially also the $30 \%$ slowdown in the north Atlantic overturning circulation during the past half century (Bryden et al., 2005). Given the grossly disappointing international political response to the required greenhouse gas emissions, and further considering some drastic results of recent studies (Andreae et al., 2005; Stainforth et al., 2005), research on the feasibility and environmental consequences of climate engineering of the kind presented in this paper, which might need to be deployed in future, should not be tabooed. Actually, considering the great importance of the lower stratosphere/upper troposphere (LS/UT) for the radiation balance, chemistry, and dynamics of the atmosphere, its research should anyhow be intensified. For instance, it is not well known how much of the large quantities of anthropogenic $\mathrm{SO}_{2}$ emitted at ground level reaches the LS/UT to produce sulfate particles, what regulates temperatures, water vapour concentrations and cirrus cloud formation in the LS/UT region, and how these factors may change in response to growing $\mathrm{CO}_{2}$ concentrations, which are already $30-40 \%$ higher than 
ever experienced during the past 650,000 years (Siegenthaler et al., 2005). Progress in the understanding of the complicated earth climate system is generally slow. Therefore it is recommended to intensify research in order to challenge the climate modification idea here presented, starting with model investigations and, dependent on their outcome, followed step by step by small scale atmospheric tests. Also, as natural sulfur injection experiments occur intermittently in the form of explosive volcanic eruptions, often at low latitudes, they provide excellent opportunities for model development and testing (e.g., Robock, 2000).

Researchers at the Lawrence Livermore Laboratory are so far the only ones who have modelled the stratospheric albedo modification scheme. In a first study, Govindasamy and Caldeira (2000) simulated this by reducing the solar luminosity by $1.8 \%$, to balance future climate warming by a doubling of $\mathrm{CO}_{2}$. Although solar radiative forcing has a different physics and spatial distribution than the infrared effects caused by $\mathrm{CO}_{2}$, the model results indicated that the global temperature response by both perturbations at the Earth' surface and atmosphere largely cancelled out. Although these preliminary model results would be in favor a stratospheric sulfur injection operation, the required annual $S$ inputs are large, so that the possibility of adverse environmental side effects needs to be fully researched before the countermeasure to greenhouse warming is attempted. What has to be done first, is to explore whether using a sulfur injection scheme with advanced micro-physical and radiation process descriptions will show similar model results as the simple solar luminosity adjustment scheme of Govindasamy and Caldeira (2000). Further studies, following those conducted by Govindasamy (2003), should address the biological effects of the albedo modification scheme. As already mentioned, injection of soot may be an alternative, but in need of critical analysis. Such studies by themselves, even when the experiment is never done, will be very informative.

Among possible negative side effects, those on stratospheric ozone first spring to mind. Fortunately, in this case one can build on the experience with past volcanic eruptions, such as El Chichón in 1982 and Mount Pinatubo in 1991, which injected 3-5 Tg S (Hofmann and Solomon, 1989) and $10 \mathrm{Tg}$ S (Bluth et al., 1992), respectively, in the stratosphere. Local ozone destruction in the El Chichón case was about 16\% at $20 \mathrm{~km}$ altitude at mid-latitudes (Hofmann and Solomon, 1989). For Mount Pinatubo, global column ozone loss was about 2.5\% (Kinnison et al., 1994). For the climate engineering experiment, in which the cooling effect of all tropospheric anthropogenic aerosol is removed, yielding a radiative heating of $1.4 \mathrm{~W} / \mathrm{m}^{2}$ (Crutzen and Ramanathan, 2003), a stratospheric loading of almost $2 \mathrm{Tg} \mathrm{S}$, and an input of 1-2 $\mathrm{Tg} \mathrm{S} / \mathrm{yr}$ is required, depending on stratospheric residence times. In this case, stratospheric sulfate injections would be 5 times less than after the Mount Pinatubo eruption, leading to much smaller production of ozone-destroying $\mathrm{Cl}$ and $\mathrm{ClO}$ radicals, whose formation depends on particle surface-catalyzed heterogeneous reactions (Wilson, 1993). Compensating for a $\mathrm{CO}_{2}$ doubling would lead to larger ozone loss but not as large as after Mount Pinatubo. Furthermore, the amounts of stratospheric chlorine radicals, coming from past production of the 
chloro-fluoro-carbon gases, are now declining by international regulation, so that ozone will significantly recover by the middle of this century. If instead of $\mathrm{SO}_{2}$, elemental carbon would be injected in the stratosphere, higher temperatures might prevent the formation of polar stratospheric ice particles and thereby hinder the formation of ozone holes. This and the consequences of soot deposition on polar glaciers should be checked by model calculations.

In contrast to the slowly developing effects of greenhouse warming associated with anthropogenic $\mathrm{CO}_{2}$ emissions, the climatic response of the albedo enhancement experiment would start taking effect within about half a year, as demonstrated by the Mount Pinatubo eruption (Hansen et al., 1992). Thus, provided the technology to carry out the stratospheric injection experiment is in place, as an escape route against strongly increasing temperatures, the albedo adjustment scheme can become effective at rather short notice, for instance if climate heats up by more than $2{ }^{\circ} \mathrm{C}$ globally or when the rates of temperatures increase by more than $0.2^{\circ} \mathrm{C} / \mathrm{decade}$ ), i.e. outside the so-called "tolerable window" for climate warming (e.g., Bruckner and Schellnhuber, 1999). Taking into account the warming of climate by up to $1{ }^{\circ} \mathrm{C}$ by air pollution reduction (Brasseur and Roeckner, 2005), the tolerable window for greenhouse gas emissions might be as low as $1{ }^{\circ} \mathrm{C}$, not even counting positive biological feedbacks. As mentioned before, regionally more rapid climate changes are already happening in the Arctic (Chapin et al., 2005) or are in petto for Africa (Cherry, 2005). Already major species extinctions by current climate warming have been reported by Pounds et al. (2005) and Root et al. (2003). If sizeable reductions in greenhouse gas emissions will not happen and temperatures rise rapidly, then climatic engineering, such as presented here, is the only option available to rapidly reduce temperature rises and counteract other climatic effects. Such a modification could also be stopped on short notice, if undesirable and unforeseen side effects become apparent, which would allow the atmosphere to return to its prior state within a few years. There is, therefore, a strong need to estimate negative, as well as positive, side effects of the proposed stratospheric modification schemes. If positive effects are greater than the negative effects, serious consideration should be given to the albedo modification scheme.

Nevertheless, again I must stress here that the albedo enhancement scheme should only be deployed when there are proven net advantages and in particular when rapid climate warming is developing, paradoxically, in part due to improvements in worldwide air quality. Importantly, its possibility should not be used to justify inadequate climate policies, but merely to create a possibility to combat potentially drastic climate heating (e.g. Andreae et al., 2005; Stainforth et al., 2005; Crutzen and Ramanathan, 2003; Anderson et al., 2003a,b). The chances of unexpected climate effects should not be underrated, as clearly shown by the sudden and unpredicted development of the antarctic ozone hole. Current $\mathrm{CO}_{2}$ concentrations are already 30-40\% larger than at any time during the past 650,000 years (Siegenthaler et al., 2005). Climate heating is known to be particularly strong in arctic regions (Chapin et al., 2005), which may trigger accelerated $\mathrm{CO}_{2}$ and 
$\mathrm{CH}_{4}$ emissions in a positive feedback mode. Earth system is increasingly in the non-analogue condition of the Anthropocene.

Reductions in $\mathrm{CO}_{2}$ and other greenhouse gas emissions are clearly the main priorities (Socolow et al., 2004; Lovins, 2005). However, this is a decades-long process and so far there is little reason to be optimistic. There is in fact a serious additional issue. Should the proposed solutions to limit $\mathrm{CO}_{2}$ emissions prove unsuccessful and should $\mathrm{CO}_{2}$ concentrations rise to high levels with risk of acidification of the upper ocean waters, leading to dissolution of calcifying organisms (Royal Society, 2005; Orr et al., 2005), underground $\mathrm{CO}_{2}$ sequestration (Lackner, 2003), if proven globally significant, will be needed to bring down atmospheric $\mathrm{CO}_{2}$ concentrations. However, that kind of sequestration does not allow for rapid remedial response. Reforestation could do so, but has its own problems. A combination of efforts may thus be called for, including the stratospheric albedo enhancement scheme.

In conclusion: The first modelling results and the arguments presented in this paper call for active scientific research of the kind of geo-engineering, discussed in this paper. The issue has come to the forefront, because of the dilemma facing international policy makers, who are confronted with the task to clean up air pollution, while simultaneously keeping global climate warming under control. Scientific, legal, ethical, and societal issues, regarding the climate modification scheme are many (Jamieson, 1996; Bodansky, 1996). Building trust between scientists and the general public would be needed to make such a large-scale climate modification acceptable, even if it would be judged to be advantageous. Finally, I repeat: the very best would be if emissions of the greenhouse gases could be reduced so much that the stratospheric sulfur release experiment would not need to take place. Currently, this looks like a pious wish.

\section{Acknowledgements}

Thanks go to many colleagues, in particular Ron Nielsen for advice on cost estimates, and to him, and colleagues V. Ramanathan, Jos Lelieveld, Carl Brenninkmeijer, Mark Lawrence, Yoya Joseph, and Henning Rodhe for advice and criticism on this paper. Part of this study was conducted during a stay at the International Institute of Advanced Systems Analysis (IIASA) in Laxenburg, Austria and discussed with Bob Ayres and Arnulf Grübler.

\section{References}

Albritton, D. L. et al.: 2001, 'Technical Summary, in Climatic Change 2001, The Scientific Basis, Intergovernmental Panel for Climate Change', in Houghton, J. T. et al. (eds.), Cambridge University Press, United Kingdom and New York, NY, USA.

Anderson, T. L. et al.: 2003a, 'Climate forcing by aerosols-A hazy picture', Science 300, 1103-1104. Anderson, T. L. et al.: 2003b, 'Response to P. J. Crutzen and V. Ramanathan, op cited', Science 302, $1680-1681$.

Andreae, M. O., Jones, C. D., and Cox, P. M.: 2005, 'Strong present-day aerosol cooling implies a hot future', Nature 435, 1187-1190. 
Bluth, G. J. S., Doiron, S. D., Schnetzler, C. C., Krueger, A. J., and Walter L. S.: 1992, 'Global tracking of the $\mathrm{SO}_{2}$ clouds from the June 1991 Mount Pinatubo eruptions', Geophys. Res. Lett. 19, 151-154.

Bodansky, D.: 1996, 'May we engineer the climate?', Clim. Change 33, 309-321.

Brasseur, G. P. and Roeckner, E.: 2005, 'Impact of improved air quality on the future evolution of climate', Geophys. Res. Letters 32, L23704, doi:10.1029/2005GL023902.

Bryden, H. L., Longworth, H. R., and Cunningham, S. A.: 2005, 'Slowing of the Atlantic meridional overturning circulation at $25 \mathrm{~N}$ ', Nature 438, 655-657.

Bruckner, T. and Schellnhuber, H. J.: 1999, 'Climate Change Protection: The Tolerable Windows Approach', IPTS Report 34, May 1999, 6.

Budyko, M. I.: 1977, 'Climatic Changes, American Geophysical Society', Washington, D.C., 244 pp.

Chapin III, F. S. et al.: 2005, 'Role of land-surface changes in Arctic summer warming', Science 310, $657-660$.

Cherry, M.: 2005, 'Ministers agree to act on warnings of soaring temperatures in Africa', Nature 437, 1217.

Chin, M. and Davis, D. D.: 1993, 'Global sources and sinks of OCS and $\mathrm{CS}_{2}$ and their distributions', Glob. Biogeochem. Cycles 7, 321-337.

Crutzen, P. J.: 1976, 'The possible importance of COS for the sulfate layer of the stratosphere', Geophys. Res. Lett. 3, 73-76.

Crutzen, P. J. and Ramanathan, V.: 2003, 'The parasol effect on climate', Science 302, 1679-1681.

Cubasch, U. et al.: 2001, 'Projections of Future Climate Change', Chapter 9, pp. 525-582.

Climate Change 2001: The Scientific Basis, Third Assessment Report of the Intergovernmental Panel on Climate Change, J. T. Houghton et al. (eds.), Cambridge University Press, Cambridge, U.K. and New York, N.Y., USA.

Dickinson, R. E.: 1996, 'Climate Engineering. A review of aerosol approaches to changing the global energy balance', Clim. Change 33, 279-290.

Govindasamy, B. and Caldeira, K.: 2000, 'Geoengineering Earth's radiative balance to mitigate $\mathrm{CO}_{2}$ induced climatic change', Geophys. Res. Lett. 27, 2141-2144.

Govindasamy, B. et al.: 2002, 'Impact of geoengineering schemes on the terrestrial biosphere', Geophys. Res. Lett. 29(22), 2061, doi.1029/2002GL015911, 2002.

Hansen, J., Lacis, A., Ruedy, R., and Sato, M.: 1992, 'Potential climate impact of Mount Pinatubo eruption', Geophys. Res. Lett. 19, 215-218.

Hofmann, D. J. and Solomon, S.: 1989, 'Ozone destruction through heterogeneous chemistry following the eruption of El Chichón', J. Geophys. Res. 94(D4), 5029-5041.

Jamieson, D.: 1996, 'Ethics and intentional climate change', Clim. Change 33, 323-336.

Keith, D. W.: 2000, 'Geoengineering the climate: History and prospect', Annu. Rev. Energy Environ. 25, 245-284.

Kinnison, D. E. et al.: 1994, 'The chemical and radiative effects of the Mount Pinatubo eruption', J. Geophys. Res. 99, 25705-25731.

Lacis, A. A. and Mishchenko, M. I.: 1995, 'Climate forcing, climate sensitivity, and climate response: A radiative modelling perspective on atmospheric aerosols', in Aerosol Forcing of Climate (Charlson R. J. and Heinztenberg, J., (eds.), 416 pp, Wiley, Chichester, pp. 11-42.

Lackner, K. S.: 2003, 'A guide to $\mathrm{CO}_{2}$ sequestration', Science 300, 1677-1678.

Lovins, A. B.: 2005, 'More profit with less carbon', Scientific American 293, 52-61.

Marland, G., Boden, T. A., and Andres, R. J.: 2005, 'Global, Regional, and National $\mathrm{CO}_{2}$ Emissions'. in Trends: A Compendium of Data on Global Change. Carbon Diozide Information Analysis Center, Oak Ridge National Laboratory, US. Department of Energy, Oak Ridge, Tenn.

National Academy of Sciences (NAS): 1992, Policy Implications of Greenhouse Warming: Mitigation, Adaptation, and the Science Base, Panel on Policy Implications of Greenhouse Warming, 
Committee on Science, Engineering, and Public Policy, National Academy Press, Washington DC, $918 \mathrm{pp}$.

Nel, A.: 2005, 'Air pollution-related illness: Effects of particles', Science 308, 804.

Orr, J. C. et al.: 2005, 'Anthropogenic ocean acidification over the twenty-first century and its impact on calcifying organisms', Science 437, 681-686.

Pinker, R. T., Zhang, B., and Dutton, E. G.: 2005, 'Do satellites detect trends in surface solar radiation?', Science 308, 850-854.

Pounds, J. A. et al.: 2005, 'Widespread amphibian extinctions from epidemic disease driven by global warming', Nature 439, 161-165.

Prentice, I. C. et al.: 2001, 'The Carbon Cycle and Atmospheric Carbon Dioxide', Chapter 3, pp. 183238, Third Assessment Report of the Intergovernmental Panel on Climate Change, Houghton, J. T. et al. (eds.), Cambridge University Press, U. K. and New York, USA.

Ramanathan, V., Crutzen, P. J., Kiehl, J. T., and Rosenfeld, D.: 2001, 'Aerosols, climate and the hydrological cycle', Science 294, 2119-2124.

Ramaswamy, V. et al.: 2001, 'Radiative Forcing of Climate Change', Chapter 6, pp. 349-416.

Climate Change 2001: The Scientific Basis, Third Assessment Report of the Intergovernmental Panel on Climate Change, Houghton, J. T. et al. (eds.), Cambridge University Press, Cambridge, U.K. and New York, N.Y., USA.

Robock, A.: 2000, 'Volcanic eruptions and climate', Rev. Geophys. 38, 191-219.

Root, T. L et al.: 2003, 'Fingerprints of global warming on wild animals and plants', Nature 421, $57-60$.

Rosenfeld, D.: 2000, 'Suppression of rain and snow by urban and industrial air pollution', Science 287, 1793-1796.

Royal Society: June 2005, Ocean acidification due to increasing atmospheric carbon dioxide, $57 \mathrm{pp}$.

Schneider, S. H.: 1996, 'Geoengineering: Could-or-Should-we do it', Clim. Change 33, 291-302.

Siegenthaler, U. et al.: 2005, 'Stable carbon cycle-climate relationship during the late Pleistocene', Science 310, 1313-1317.

Socolow, R. et al.: 2004, 'Solving the climate problem', Environment 46, 8-19.

Stainforth, D. A. et al.: 2005, 'Uncertainty in predictions of the climate response to rising levels of greenhouse gases', Nature 433, 403-406.

Stern, D. I.: 2005, 'Global sulfur emissions from 1850 to 2000', Chemosphere 58, 163-175.

Teller, E., Wood, L., and Hyde, R.: 1997, 'Global warming and ice ages: 1. Prospects for physics based modulation of global change', UCRL-JC-128157, Livermore National Laboratory, Livermore, CA.

Wild, M. et al.: 2005, 'From dimming to brightening: Decadal changes in solar radiation and Earth's surface', 308, 847-850.

Wilson, J. C. et al.: 1993, 'In-situ observations of aerosol and chlorine monoxide after the 1991 eruption of Mount Pinatubo: Effect of reactions on sulfate areosol', Science 261, 1140-1143.

Max-Planck-Institute for Chemistry

PAUL J. CRUTZEN

Department of Atmospheric Chemistry

P.O. Box 3060, 55020 Mainz, Germany

E-mail:crutzen@mpch-mainz.mpg.de

and

Scripps Institution of Oceanography

University of California, San Diego

9500 Gilman Drive MC 0239-0221

La Jolla, CA 92093-0239, USA

E-mail: crutzen@fiji.ucsd.edu 